九州大学学術情報リポジトリ

Kyushu University Institutional Repository

\title{
Processing Pure Ti by High-Pressure Torsion in Wide Ranges of Pressures and Strain
}

\section{Edalati, Kaveh}

Department of Materials Science and Engineering, Faculty of Engineering, Kyushu University

Matsubara, Ei ichiro

Department of Materials Science and Engineering, Faculty of Engineering, Kyoto University

Horita, Zenji

Department of Materials Science and Engineering, Faculty of Engineering, Kyushu University

http://hdl. handle. net/2324/26392

出版情報: Metallurgical and Materials Transactions A. 40 (9)，pp.2079-2086，2009-09-01. Springer US

バージョン :

権利関係: (C) The Minerals, Metals \& Materials Society and ASM International 2009 


\title{
Processing Pure Ti by High-Pressure Torsion in Wide Ranges of Pressures and Strain
}

\author{
Kaveh Edalati $^{\mathrm{a}, *}$, Eiichiro Matsubara ${ }^{\mathrm{b}}$ and Zenji Horita ${ }^{\mathrm{a}}$ \\ a Department of Materials Science and Engineering, Faculty of Engineering, Kyushu University, \\ Fukuoka 819-0395, Japan \\ b Department of Materials Science and Engineering, Faculty of Engineering, Kyoto University, \\ Kyoto 606-8501, Japan
}

\begin{abstract}
Pure Ti (99.4 pct) is processed by high-pressure torsion (HPT) at applied pressures in a wide range of 1.2 to 40 giga-pascals (GPa) for equivalent strain up to 200 . X-ray diffraction (XRD) analysis clearly reveals that a pressure-induced phase transformation occurs from $\alpha$ phase to $\omega$ phase during HPT processing when the applied pressure is more than $\sim 4 \mathrm{GPa}$ and the straining facilitates this phase transformation. The hardness and the tensile strength increase, but the ductility decreases by the phase transformation. Hardness measurements demonstrate that all values obtained at each pressure fall on a single curve when they are plotted as a function of equivalent strain. The hardness increases with an increase in the equivalent strain at an early stage of straining and saturates to a constant level, where the hardness remains unchanged with further straining. It is shown that the saturation level as well as the onset of the saturation depends on the applied pressure.
\end{abstract}

* Contact e-mail: kaveh.edalati@zaiko6.zaiko.kyushu-u.ac.jp 


\section{Introduction}

To achieve ultra fine grained (UFG) materials with grain sizes in the nanometer or sub-micrometer level, a great attention has been allocated to the application of severe plastic deformation (SPD) [1-6]. Grain refinement using the SPD leads to an increase in the strength with reasonable ductility without addition of alloying elements. Pure $\mathrm{Ti}$ is a typical material in SPD-related researches because of its biomedical application [7-9].

Different SPD methods have been utilized for processing of Ti. They are high pressure torsion (HPT) [10-12], equal-channel angular pressing (ECAP) [13, 14], ECAP followed by HPT [15, 16], ECAP followed by cold rolling [17-19], accumulative roll-bonding (ARB) [20], multi-directional forging (MDF) [21], and hydrostatic extrusion (HE) [22, 23].

In the HPT method, a thin disc sample is placed between two anvils under a high pressure and intense shear strain is introduced by rotating the two anvils with respect to each other. Best to the authors' knowledge, little is understood regarding the influence of the applied pressure on the mechanical properties and microstructures in HPT-processed Ti. The pressure for the HPT is normally in the range of several giga-pascals (GPa) but few is attempted with pressures higher than 8 GPa except the application of 20 GPa for Fe [24].

Pure Ti may transform from an $\alpha$ phase with the hcp crystal structure to an $\omega$ phase with the simple hexagonal structure [25-28]. This phase transformation was observed using a diamond anvil cell at more than pressures from 2.9 GPa [27] to 11 GPa [28]. Errandonea et al. [29] showed that such a pressure range for initiating the phase transformation is attributed to the presence of non-hydrostatic conditions arising from the difference in pressurizing media. The existence of a $\beta$-phase with the bcc structure in Ti was also theoretically predicted at pressures higher than $36 \mathrm{GPa}$, but this transformation has never been observed experimentally [30, 31]. Literature survey concludes that, in spite of the numerous studies concerning the effect of pressure on the phase transformations in pure $\mathrm{Ti}$, there are limited works on the role of strain for the pressure-induced phase transformations in $\mathrm{Ti}$ [32, 33]. Kilmametov et al. [32] reported that the formation of an $\omega$ phase occurred in Ti even under a pressure of $3 \mathrm{GPa}$ when HPT is used. Furthermore, it was reported that the fraction of $\omega$ phase increases with increasing pressure from 3 to $6 \mathrm{GPa}$ and with increasing shear strain. All these results suggest the importance of not only pressure but also strain for the phase transformation in Ti.

In the present investigation, commercial pure $\mathrm{Ti}$ is processed by HPT to examine the evolution of mechanical properties and microstructural features including phase transformation. Both applied pressure and imposed strain are varied over wide ranges such that the pressure is raised up to $40 \mathrm{GPa}$, which is the largest pressure attempted in the HPT studies and the equivalent strain of up to 200 is produced by increasing the number of revolutions in HPT.

\section{Experimental Materials and Procedures}

A rod of commercial pure Ti (99.4\%) with $10 \mathrm{~mm}$ diameter and $70 \mathrm{~mm}$ length was used in this study. The Ti rod had impurities of $\mathrm{H} \mathrm{0.013,} \mathrm{O} \mathrm{0.20,} \mathrm{N} \mathrm{0.05,} \mathrm{Fe} 0.25$ in weight percent. The rod was annealed for 1 hour at $1073 \mathrm{~K}$ under an argon atmosphere and sliced to discs with thicknesses 
of $0.85 \mathrm{~mm}$ using a wire-cutting electric discharge machine. In addition, disc samples with $4 \mathrm{~mm}$ diameter and $0.85 \mathrm{~mm}$ thickness were prepared for pressures higher than $6 \mathrm{GPa}$.

HPT was carried out on the annealed discs. Two sets of upper and lower anvils with a circular flat-bottom hole at the center were used to process the disc samples where the hole depths were $0.25 \mathrm{~mm}$ and hole diameters were 4 or $10 \mathrm{~mm}$, respectively. The disc samples with $10 \mathrm{~mm}$ diameter were processed to either $1 / 2,1,2$, 4 or 10 revolutions with rotation speeds of 0.2 and 0.5 rpm under a selected load in the range of 9.6-48 tons. These loads are equivalent to the pressures in the range of 1.2-6 GPa. The disc samples with $4 \mathrm{~mm}$ diameter were processed with a rotation speed of $0.2 \mathrm{rpm}$ under a selected load in the range of 17.5-50 tons for 5 revolutions and these loads are equivalent to the pressures in the range of 14-40 GPa. It should be noted that the pressure was calculated by dividing the applied load by the area of the central hole on the anvil. Nevertheless, the pressure was not rigorously evaluated in this study because of the difficulty in direct measurement under very restricted condition so that it should be taken as the nominal pressure in this study. A thermocouple located at the center of the upper anvil and at the position $10 \mathrm{~mm}$ away from the surface was used to check the temperature rise during HPT.

The disc samples with $10 \mathrm{~mm}$ diameter after HPT were evaluated in terms of Vickers microhardness, tensile properties, microstructures and X-ray diffraction (XRD). First of all, after processing by HPT, disc samples were polished to a mirror-like surface and the Vickers microhardness was measured with an applied load of $200 \mathrm{~g}$ for $15 \mathrm{~s}$ along the radii from the center to edge at 8 different radial directions with $0.5 \mathrm{~mm}$ increments as drawn by dotted lines in Fig. 1 for $10 \mathrm{~mm}$ discs. For the $4 \mathrm{~mm}$ discs, the hardness measurements were undertaken at positions $1.5 \mathrm{~mm}$ away from the center in 8 radial directions after polishing to a mirror-like surface.

Second, miniature tensile specimens having $1 \mathrm{~mm}$ gauge length, $1 \mathrm{~mm}$ width and $0.5 \mathrm{~mm}$ thickness were cut from the $10 \mathrm{~mm}$ discs at the position $2 \mathrm{~mm}$ away from the center as illustrated in Fig. 1. Each tensile specimen was mounted horizontally on grips and pulled to failure using a tensile testing machine with an initial strain rate of $3.3 \times 10^{-3} \mathrm{~s}^{-1}$. The stress-strain curve was plotted for each specimen and the ultimate tensile strength and elongation to failure were measured from the curves. It should be noted that the dimensions of the present tensile specimens are fairly small and therefore, care is required when compared with other dimensions of tensile specimens as pointed out by Zhao et al. [34].

Third, for transmission electron microscopy (TEM), discs with 3mm diameter were punched out from the 10mm HPT discs at $3.5 \mathrm{~mm}$ away from the center as illustrated in Fig. 1. The 3mm discs were ground mechanically to a thickness of $0.15 \mathrm{~mm}$ and further thinned for electron transparency with a twin-jet electro-chemical polisher using a solution of $4 \% \mathrm{HClO}_{4}, 25 \%$ $\mathrm{C}_{3} \mathrm{H}_{3}\left(\mathrm{CH}_{2}\right)_{2} \mathrm{CH}_{2} \mathrm{OH}$ and $69 \% \mathrm{CH}_{3} \mathrm{OH}$ at $243 \mathrm{~K}$ under an applied voltage of $10 \mathrm{~V}$. A Hitachi H-8100 transmission electron microscope (Hitachi Naka-shi, Ibaraki, Japan) was operated at $200 \mathrm{kV}$ for microstructural observation. Selected area electron diffraction (SAED) patterns were taken from a region with $6.3 \mu \mathrm{m}$ diameter to complement the TEM observation.

Fourth, disc samples processed under different pressures including an annealed disc before HPT were polished to a mirror-like surface and the structural analysis with XRD were performed 
using the Co $\mathrm{K} \alpha$ radiation $\left(\lambda=1.79 \mathrm{~A}^{\circ}\right)$ in a scanning step of $0.01^{\circ}$ and a scanning speed of $2 \% \mathrm{~min}$.

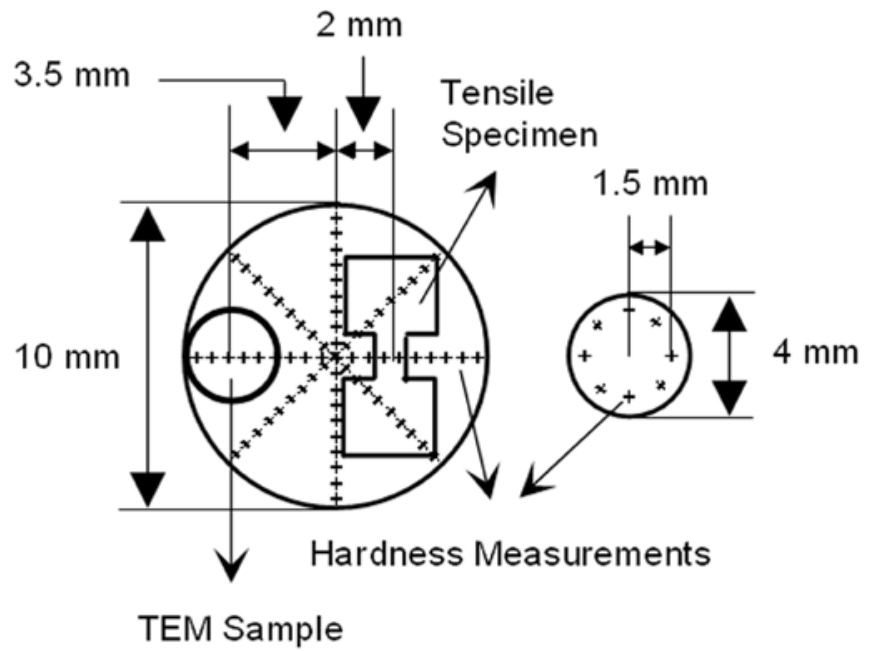

Figure 1. Schematic illustration of HPT discs and procedures for microhardness measurements, and locations for TEM disc and tensile testing specimen.

\section{Results}

Microhardness measurements have confirmed that the hardness increases with the distance from the disc center for all numbers of revolutions and the hardness level is higher for larger numbers of revolutions as in other reports [4, 35-37]. All hardness values are then plotted against the equivalent strain in Fig. 2 as attempted earlier on $\mathrm{Al}$ [38, 39], $\mathrm{Cu}$ [35, 39] and Fe [36]. Here, the equivalent strain was calculated through the following equation [36].

$$
\varepsilon=(1-s) \int_{0}^{\theta} \frac{r}{\sqrt{3} t(\theta)} d \theta
$$

where $s$ is the fraction of slippage, $r$ is the distance from the disc center, $\theta$ is the rotation angle in radian and $t$ is the thickness of disc. This equation is a modified form presented earlier [39] and it takes into account the effects of the slippage between the sample and anvil and of the thickness reduction during HPT operation. The applicability and importance of this equation were given in a recent paper [36]. In this study, the values of $s$ were measured as $0.23,0.19$ and 0.03 for the applied pressures of 1.2, 2 and 6 GPa, respectively, following the manner as described earlier [40]. Because $t$ was changed with $\theta$, the functional forms of $t(\theta)$ were determined for the three different pressures as described in the Appendix.

Figure 2 shows that all points tend to fall on a single curve for each pressure but deviation occurs in Figs. 2(b) and (c), which corresponds to the samples processed for 4 and 10 revolutions with a rotation speed of $0.5 \mathrm{rpm}$. This deviation can be attributed to heat generation in these 
samples. More details for the temperature rise are discussed later. The microhardness increases with increasing equivalent strain at early stages of straining but saturates to steady levels where the hardness remains unchanged with further straining. The microhardness at the saturated level is the same for the applied pressures of 1.2 and $2 \mathrm{GPa}$ but is higher for the pressure of $6 \mathrm{GPa}$. The critical equivalent strain at the onset of the saturation is $\sim 20, \sim 10$ and $\sim 50$ for the applied pressures of 1.2, 2 and $6 \mathrm{GPa}$, respectively.
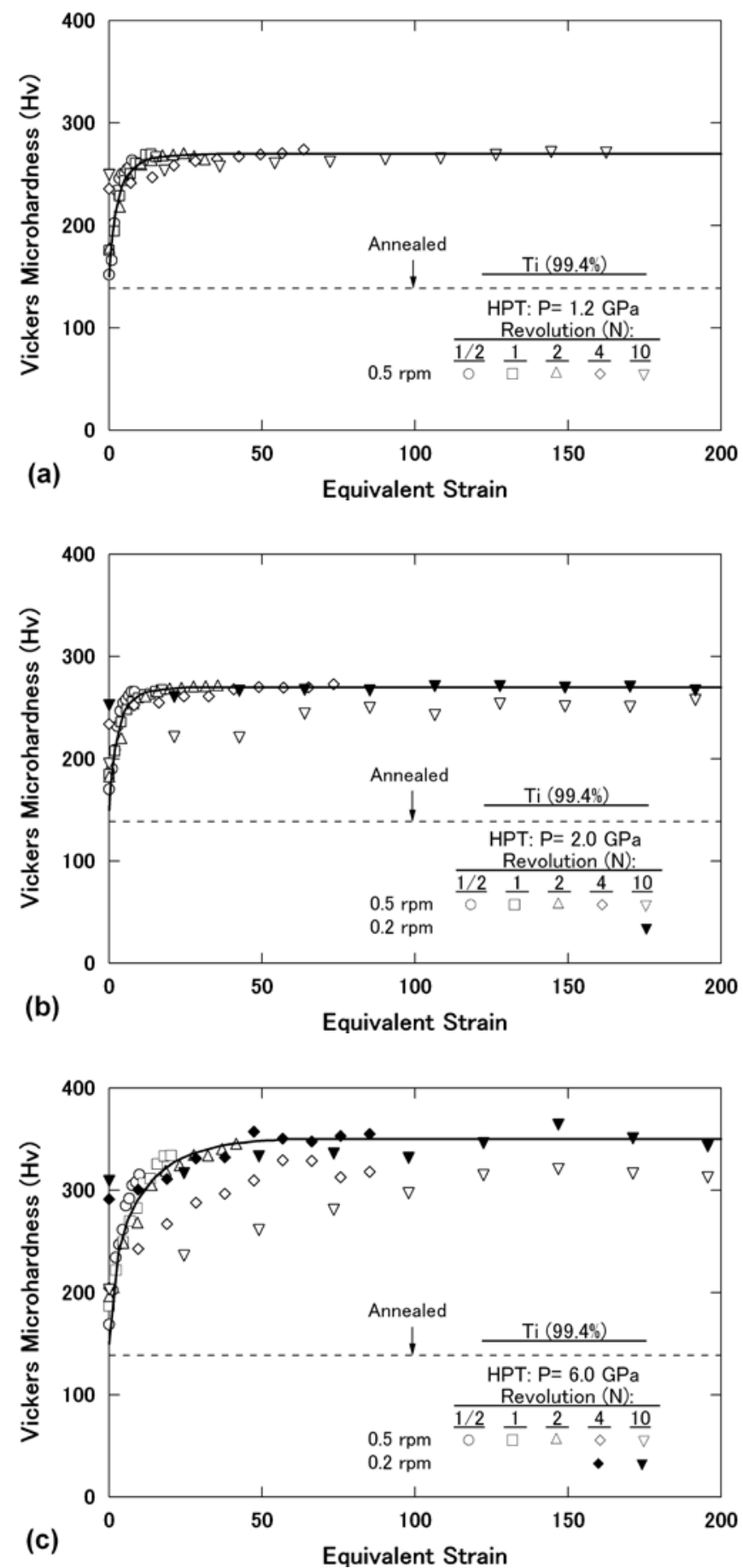

Figure 2. Vickers microhardness plotted against equivalent strain for samples processed under pressures of (a) $1.2 \mathrm{GPa}$, (b) $2 \mathrm{GPa}$ and (c) $6 \mathrm{GPa}$ and various revolutions. 
The microhardness at the saturation is plotted in Fig. 3 as a function of the applied pressure for an extended range to $40 \mathrm{GPa}$ covered in this study. The saturation microhardness is almost constant until the abrupt increase occurs at a pressure of $4 \mathrm{GPa}$ and, with a further increase in the pressure, the saturation hardness gradually increases over a range up to $40 \mathrm{GPa}$.

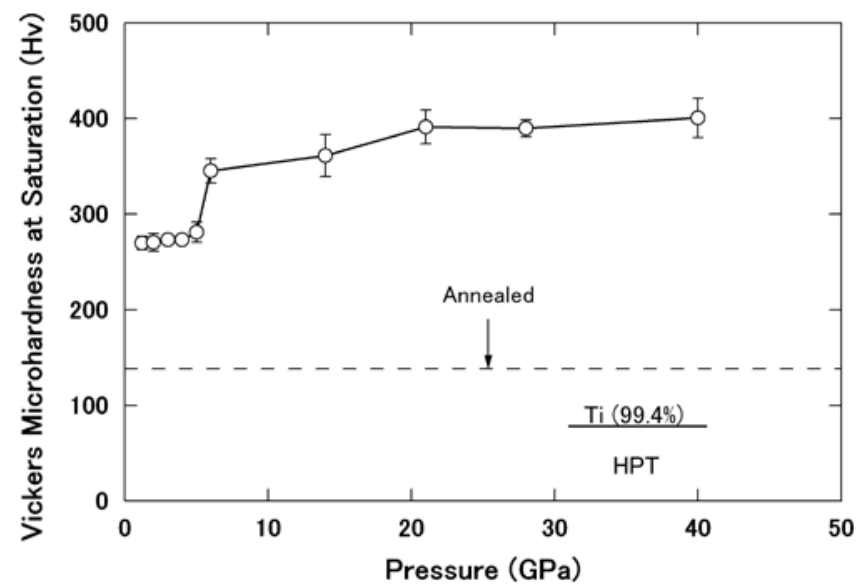

Figure 3. Plots of Vickers microhardness at saturation with respect to pressure.

The variations of the ultimate tensile strength (UTS) and the total elongation to failure are plotted against the applied pressure in Fig. 4(a) and (b), respectively, for samples after 10 revolutions. The tensile specimens were prepared $2 \mathrm{~mm}$ away from the disc center as shown in Fig. 1 so that the tensile properties reflect the saturated levels. The UTS is almost constant for the pressures up to $4 \mathrm{GPa}$ followed by an increase in the tensile strength at 5 and $6 \mathrm{GPa}$. This trend is very similar to the hardness variation shown in Fig. 3. The variation of the total elongation to failure is opposite to the UTS: the elongation to failure remains almost constant for the applied pressures up to $4 \mathrm{GPa}$ but decreases with further increasing the pressure and reaches zero at the pressure of 6 GPa.

TEM microstructures were shown in Fig. 5 for samples after 10 revolutions under three different pressures, (a)-(b) 1.2 GPa, (c)-(d) 2 GPa and (e)-(f) 6 GPa. A bright-field image (left) and a dark-field image (right) including the corresponding SAED pattern (center) were shown for each pressure. Note that the dark field images were taken with the diffracted beams indicated by arrows in the SAED patterns. It should be noted that all TEM samples were prepared from the positions away from the center as shown in Fig. 1 and they correspond to the saturated levels. Microstructural observations show that the microstructure consists of small grains with sub-micrometer sizes and the grain boundaries are in high angles of misorietation. These microstratural features are common at the three applied pressures and are similar to earlier observations of not only $\mathrm{Ti}$ and $\mathrm{Ti}$ alloys [10-16] but also other metallic materials [35, 36]. However, measurements from several dark field images reveal that the grain size for the pressure of $6 \mathrm{GPa}$ is appreciably finer than that for the pressure of $1.2 \mathrm{GPa}$ : $200 \mathrm{~nm}$ for $1.2 \mathrm{GPa}$ and $150 \mathrm{~nm}$ for $6 \mathrm{GPa}$. It is considered that this is due to the formation of the $\omega$ phase which acted as an inhibitor for the motions of dislocations and grain boundaries. 

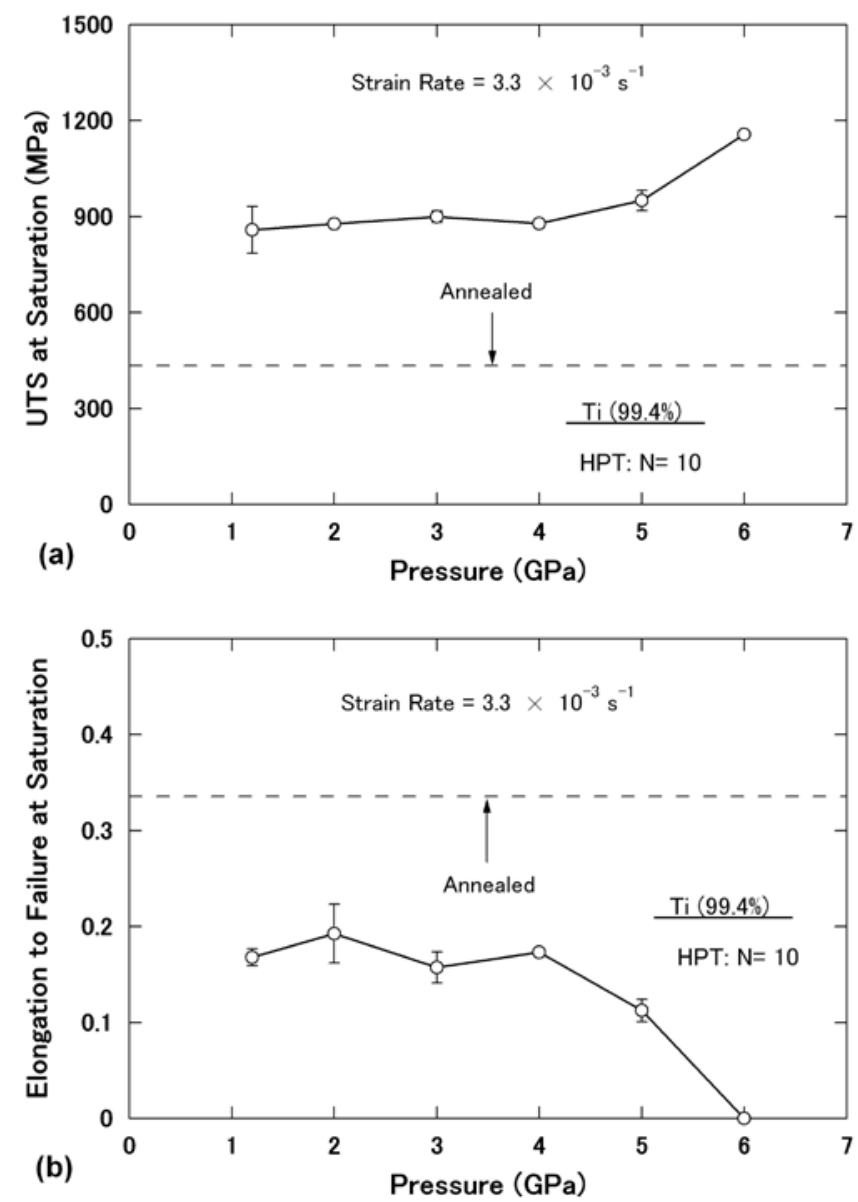

Figure 4. Plots of (a) ultimate tensile strength at saturation and (b) elongation to failure at saturation with respect to pressure.

Figure 6 shows XRD profiles for samples processed at a pressure in the range of 1.2 to 40 GPa including the annealed sample. The peak for an $\omega$ phase clearly appears above the pressure of 4 GPa and this formation is consistent with earlier studies reporting the transformation from $\alpha$ phase to $\omega$ phase at a pressure of 2.9-11 GPa [27-29]. It is also found from Fig. 6 that the fraction of the $\omega$ phase increases with the applied pressure because the relative peak heights of the $\omega$ phase to the $\alpha$ phase increase with the applied pressure above $4 \mathrm{GPa}$.

XRD profiles for different numbers of revolutions at an applied pressure of 6 GPa are shown in Fig. 7. No visible peak is detected for the $\omega$ phase after application of the pressure but without rotation. However, a peak for the $\omega$ phase clearly appears after rotation by $1 / 2$ and the peak height increases with further revolution. This indicates that no phase transformation occurs by mere application of the pressure and the straining is effective for the phase transformation. A comparison of the peak heights between the $\alpha$ phase and the $\omega$ phase in Fig. 7 reveals that there should be an intimate crystallographic correlation between the formation of the $\omega$ phase and disappearance of the $\alpha$ phase. This is because the relative intensity of the $(1010)_{\omega}$ peak to the $(0002)_{\alpha}$ peak is increased with straining despite the fact that the $(1011)_{\alpha}$ peak remains the same height. It is suggested that the formation of the $\omega$ phase may occur by rearrangement of atoms in the $(0002)_{\alpha}$ plane in consistence with earlier reports [26, 41]. 

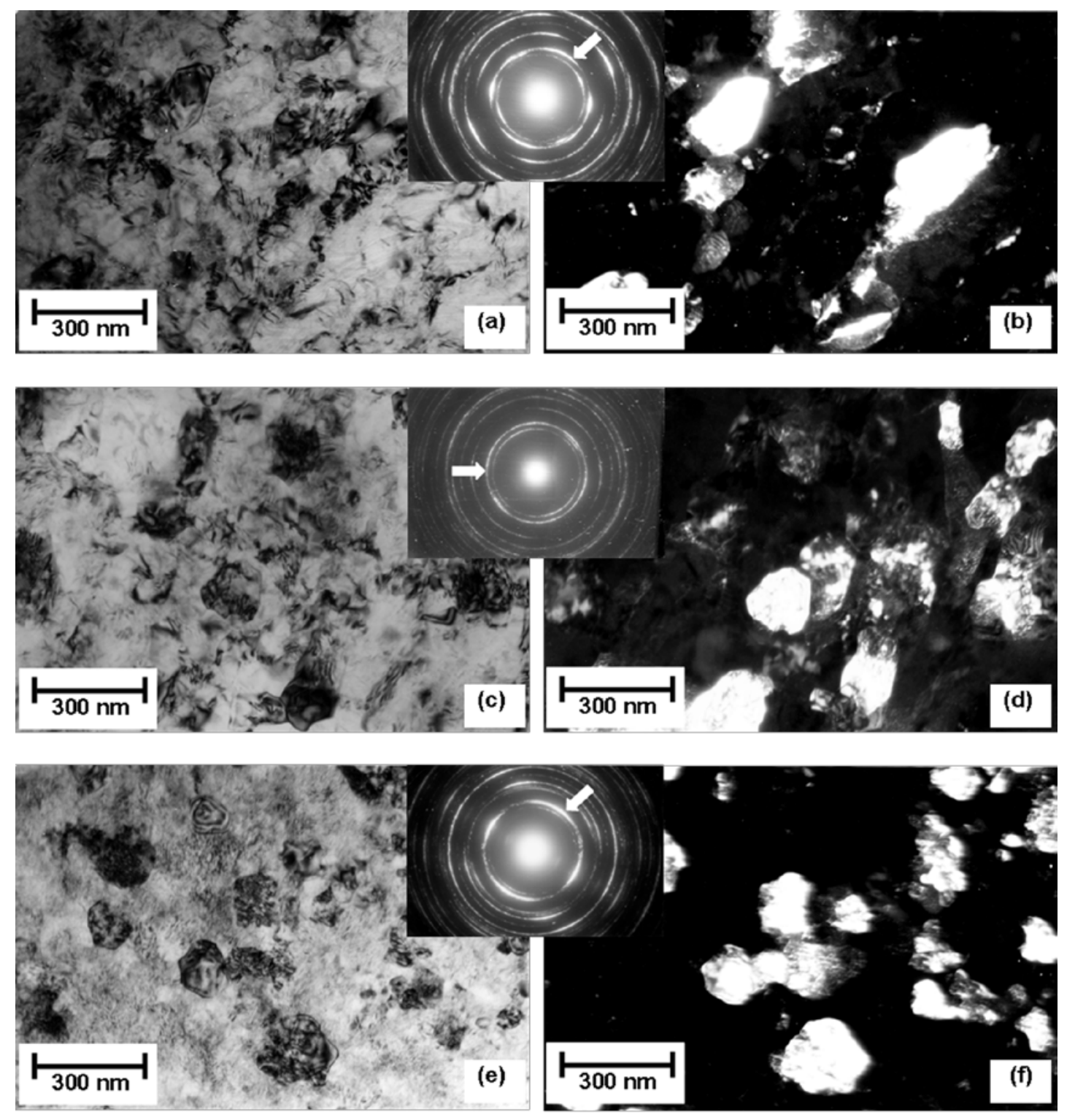

Figure 5. TEM bright- and dark-field images and SAED patterns for samples processed under pressures of (a) and (b) $1.2 \mathrm{GPa}$, (c) and (d) $2 \mathrm{GPa}$, (e) and (f) $6 \mathrm{GPa}$ after 10 revolutions.

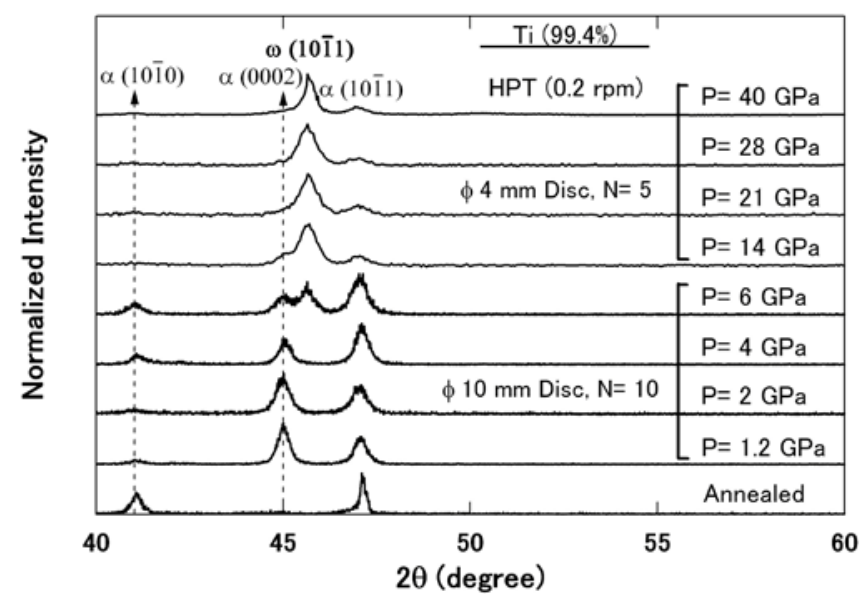

Figure 6. XRD profiles of Ti at steady state under pressures in range of $P=1.2-40 \mathrm{GPa}$ including annealed sample. 


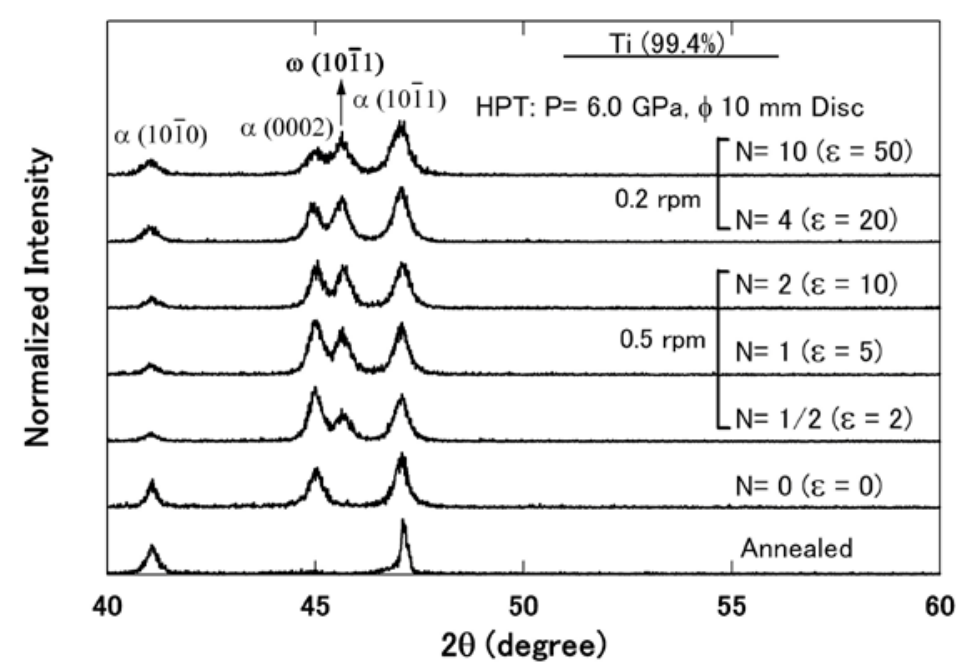

Figure 7. XRD profiles of Ti processed at 6 GPa for revolutions of $N=1 / 2-10$ including annealed sample.

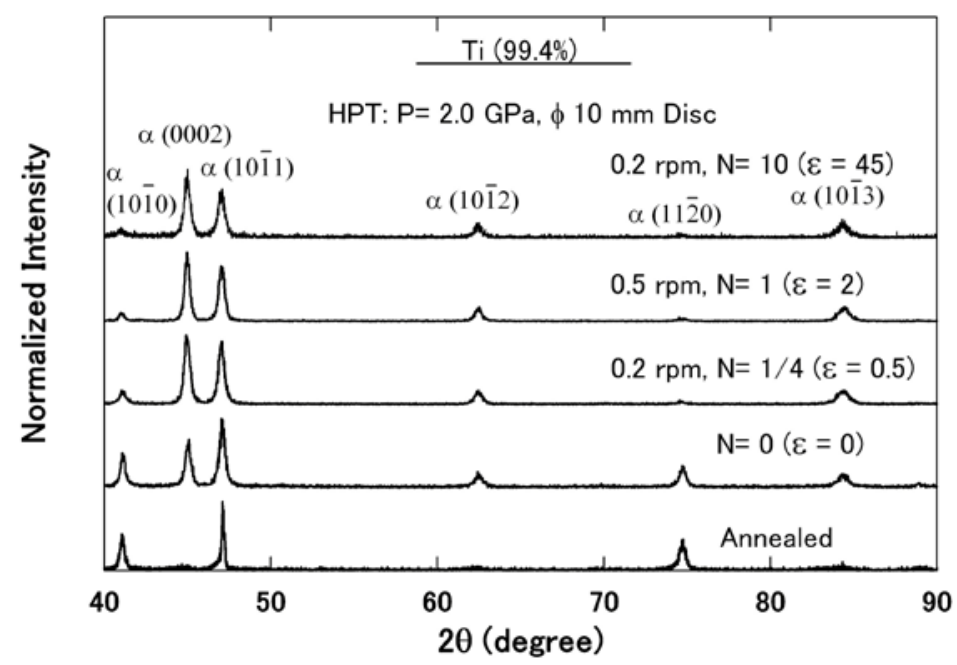

Figure 8. XRD profiles of Ti processed at 2 GPa and after various revolutions including annealed sample.

Figure 8 shows XRD profiles for the discs subjected to HPT at a pressure of $2 \mathrm{GPa}$. No $\omega$-phase peaks are present because the applied pressure is less than $4 \mathrm{GPa}$. Not only the peak broadening but also the change in peak height occurs significantly by compression and subsequent rotation through HPT: in particular, the $(0002)_{\alpha}$ peak appears strongly. The appearance of the $(0002)_{\alpha}$ peak indicates that a texture develops at the early stages of torsional straining such that the basal planes of the $\alpha$ phase with the hcp crystal structure tend to be parallel to the disc surface. This is reasonable because the basal planes are oriented to be parallel to the shear plane by the compression and subsequent rotation through HPT. More importantly, the absence of the $\omega$-phase peaks indicates that the pressure more than a critical value is required for the phase transformation to occur. The straining is then to assist the phase transformation to proceed but not the factor to initiate the transformation. 


\section{Discussions}

This study has clearly demonstrated that the phase transformation occurs from $\alpha$ phase to $\omega$ phase during HPT processing. The applied pressure is an important factor to initiate the phase transformation and it is necessary to apply a pressure more than a critical value which was about 4 GPa in this study. The straining is also important but it has a role to facilitate the phase transformation but not to initiate it. It should be important to note that the fraction of the $\omega$ phase was confirmed to remain constant even after keeping for 400 days at ambient pressure following processing by HPT at 6 GPa for 10 revolutions. This indicates that the straining is also important to inhibit the reverse transformation.

Close observation of Fig. 2(b) and (c) shows that, if the rotation speed is high (as $0.5 \mathrm{rpm}$ ) and the revolution numbers are large (as 10), the hardness level is lowered. It is considered that this is due to the heat generation and subsequent temperature rise during HPT processing. The heat generation should be more intense as the imposed strain is larger, the strain rate is higher, and the applied pressure is higher. Thus, to check the effect of temperature rise on the hardness level, the two additional measurements were carried out in this study.

First, the temperature was recorded during HPT with an anvil having a hole for a thermocouple which was terminated at a position $10 \mathrm{~mm}$ from the disc sample. The measurements showed that the temperature increases with increasing the number of revolutions, the rotation speed and the loading pressure. In fact, this tendency is consistent with the downward deviation of data points shown in Fig. 2(b) and (c). Although the temperature rise was small to reach $\sim 45{ }^{\circ} \mathrm{C}$ at the conditions for $N=10$ and $P=2 \mathrm{GPa}$ with a rotation speed of $0.5 \mathrm{rpm}$, the true temperature on the sample should be higher than the measured one due to the position of thermocouple which is $10 \mathrm{~mm}$ away from the small sample in the massive anvils.

Second, differential scanning calorimetry (DSC) experiments confirmed that reverse transformation from $\omega$ to $\alpha$ phase occurs at $150{ }^{\circ} \mathrm{C}$. The temperature rise might have reached the temperature of $150{ }^{\circ} \mathrm{C}$ and it can be sufficient to cause a reverse transformation from $\omega$ phase to $\alpha$ phase. It is reasonable that lowering the hardness is more pronounced as shown in Fig. 2(c) for $N=10$ at $P=6 \mathrm{GPa}$.

Further examination of Fig. 2(a) and (b) shows that the hardness increases more rapidly with increasing equivalent strain as the pressure increases from 1.2 to $2 \mathrm{GPa}$ and the critical equivalent strain for the saturation decreases from $\sim 20$ to $\sim 10$. However, the saturation level is independent of the applied pressure for up to $4 \mathrm{GPa}$ as shown in Fig. 3. This trend is consistent with the behavior of pure $\mathrm{Cu}$ and $\mathrm{Fe}$ [42] and can be accounted for by the idea that high pressures suppress atomic diffusion and dislocation recovery $[43,44]$ to increase dislocation density and thus to saturate more readily to the constant level. For the pressures higher than $4 \mathrm{GPa}$, the hardness gradually increase to the level in saturation and the critical equivalent strain is increased to $\sim 50$ at the pressure of 6 GPa as in Fig. 2(c). This should be due to a strain-assisted $\omega$-phase formation and thus the amount of the $\omega$ phase is increased to the equilibrium fraction determined by the applied pressure. The hardness at the saturation gradually increases with the pressure as shown in Fig. 3 because of an increase in the equilibrium fraction of the $\omega$ phase which is known to be harder than 
the $\alpha$ phase [26]. It should be noted that, because the grain size becomes finer as commented in Fig. 5 , this grain refinement can be another cause for increasing the hardness at the pressures above $4 \mathrm{GPa}$.

There may be an additional factor to discuss the effect on the microstructural development and subsequent mechanical properties. That is the strain rate which is expressed as a function of the distance from the disc center as readily derived from Eq.(1). As shown in Fig. 2, all hardness values are well on a single curve for a given applied pressure despite the fact that the strain rate is different. This suggests that the effect of strain rate on the mechanical properties is little significant within the magnitude (0-0.2 s $\left.\mathrm{s}^{-1}\right)$ covered in this study when compared with the effect of strain.

Based on the results obtained in this study, the hardness behavior of Ti with straining by HPT is delineated in Fig. 9 for different applied pressures. For the pressure below 4 GPa where no phase transformation occurs, the hardness increases with straining and saturates to a constant level which was $265 \mathrm{Hv}$ in this study. The critical strain to saturation becomes smaller as the pressure increases. When the transformation occurs as the pressure exceeds the critical value, the hardness gradually increases with straining. The transformation can be assisted by straining and the gradual increase in hardness continues until it reaches a constant level. The hardness increase can be due to the increase in the fraction of $\omega$ phase which is harder than the $\alpha$ phase but, in addition, the grain refinement by intense straining may contribute to the hardness increase. For the applied pressure well above the critical pressure, the hardness behavior is given by the broken lines. The $\omega$ phase dominates the whole sample from an early stage of straining. This hardness behavior with strain can be very similar to the case where the pressure below $4 \mathrm{GPa}$ is applied except that the former hardness level is higher than latter.

Finally, it is commented that no peak related to a $\beta$ phase was detected in the XRD profiles obtained at higher applied pressures even after intense straining. Although the formation of the $\beta$ phase with the bcc structure in Ti was theoretically predicted at pressures higher than $36 \mathrm{GPa}$, this transformation was not observed in this study as in earlier reports [30, 31].

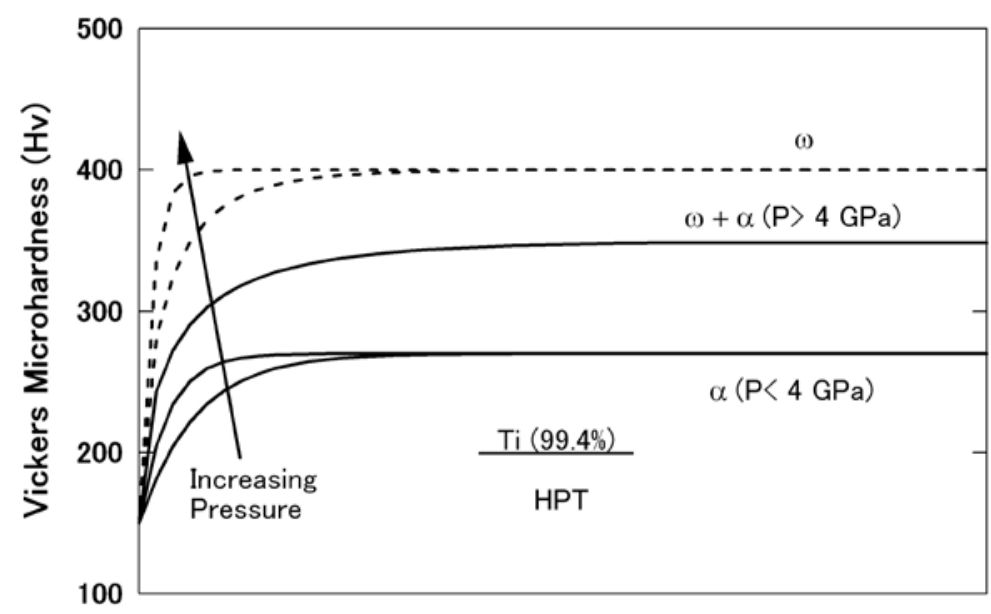

Equivalent Strain

Figure 9. Illustration of hardness behavior of Ti with straining based on HPT experiments. 


\section{Conclusions}

1. The phase transformation occurs from $\alpha$ phase to $\omega$ phase during HPT processing of commercial pure Ti (99.4\%). The applied pressure is an important factor to initiate the phase transformation and the straining has a role to facilitate the $\alpha$ to $\omega$ phase transformation.

2. For the phase transformation to occur, it is necessary to apply a pressure more than $\sim 4 \mathrm{GPa}$. The strain rate is little significant on the $\alpha$ to $\omega$ transformation. The reverse transformation from $\omega$ to $\alpha$ phase occur when the temperature increases more than $\sim 150{ }^{\circ} \mathrm{C}$.

3. The $\alpha$ to $\omega$ transformation leads to an increase in the hardness and UTS but to a decrease in the ductility in the pressure range more than 4 GPa.

4. When all hardness values at each applied pressure are plotted as a function of equivalent strain, they lie well on a single curve. The hardness increases with an increase in the equivalent strain and saturates into a steady state level. The deviation from the curve is due to heat generation and subsequent temperature rise during HPT processing.

5. The critical equivalent strain for entering the saturation level decreases with increasing the applied pressure but below the pressure for the phase transformation $(<\sim 4 \mathrm{GPa})$ and this is in consistence with other pure metals. However, the critical equivalent strain increases for the pressures ( $>4 \mathrm{GPa}$ ) where the phase transformation occurs.

6. XRD analysis confirmed that the phase transformation from $\alpha$ phase to $\omega$ phase occurs with an atomic rearrangement of the $(0002)_{\alpha}$ plane and the fraction of $\omega$ phase increases with straining and pressure.

\section{Acknowledgement}

One of the authors (KE) would like to thank the Islamic Development Bank for a scholarship. This work was supported in part by the Light Metals Educational Foundation of Japan, in part by a Grant-in-Aid for Scientific Research from the Ministry of Education, Culture, Sports, Science and Technology, Japan, in Priority Areas "Giant Straining Process for Advanced Materials Containing Ultra-High Density Lattice Defects" and in part by Kyushu University Interdisciplinary Programs in Education and Projects in Research Development (P\&P).

\section{Appendix}

Figure A1 plots the thickness as a function of $\theta$ measured after HPT at three different pressures, 1.2, 2 and $6 \mathrm{GPa}$. The measurements were made using a micrometer with an accuracy of $\pm 0.002 \mathrm{~mm}$ and it was found that the discs after HPT were acceptably flat with the maximum difference of $0.02 \mathrm{~mm}$ along the radius. The thickness decreases rapidly within the first few revolutions and gradually thereafter. The variation with respect to rotation angle can be best expressed with the forms given in the figures. For each equation, the value of the first term, 0.5, arises because the thickness never decreases below $0.5 \mathrm{~mm}$ due to the hole depth of $0.25 \mathrm{~mm}$ for each of the upper and lower anvils. The second term represents the reduction in thickness with rotation angle. With such fitting functions, the thickness is $0.85 \mathrm{~mm}$ when the rotation angle is zero, which represents the initial thickness of disc, and the thickness reaches $0.5 \mathrm{~mm}$ when the rotation 
angle is infinitely large.

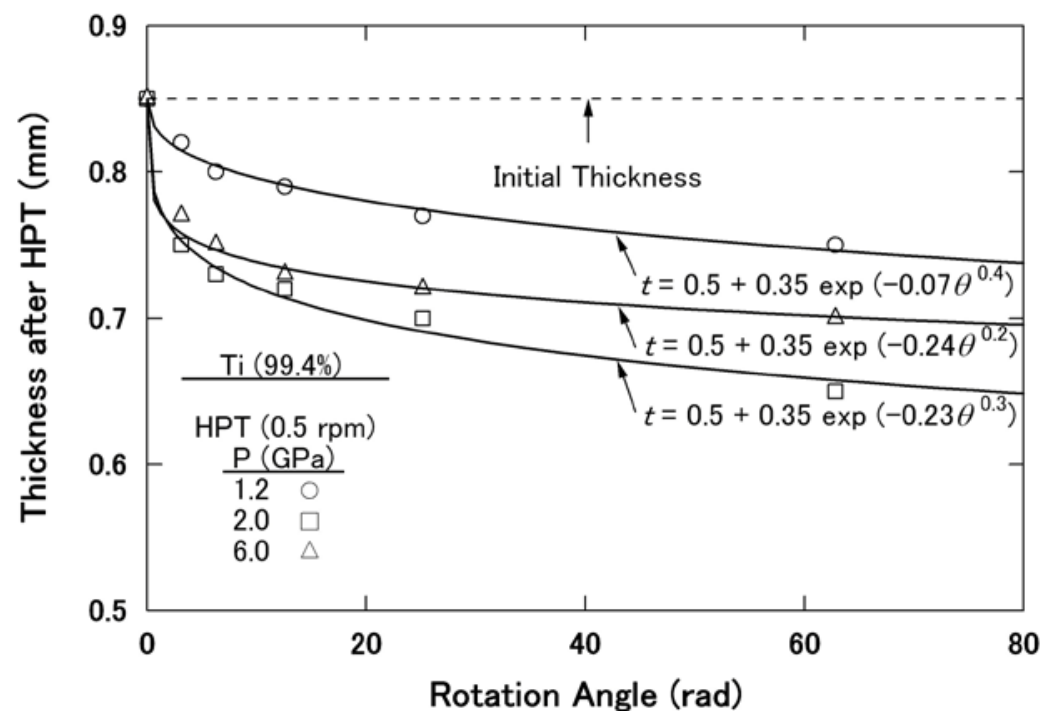

Figure A1. Thickness after HPT plotted against rotation angle for samples processed at different pressures. Lines with equations represent fitting.

\section{References}

1. R.Z. Valiev, R.K. Islamgaliev and I.V. Alexandrov: Prog. Mater. Sci., 2000, vol.45 pp. 103-189.

2. Y. Iwahashi, Z. Horita, M. Nemoto and T.G. Langdon: Acta Mater., 1997, vol. 45, pp. 4733-4741.

3. Y. Iwahashi, Z. Horita, M. Nemoto and T.G. Langdon: Acta Mater., 1998, vol. 46, pp. 3317-3331.

4. G. Sakai, Z. Horita and T.G. Langdon : Mater. Sci. Eng. A, 2005, vol. 393, pp. 344-351.

5. N.A. Smirnova, V.I. Levit, V.I. Pilyugin, R.I. Kuznetsov, L.S. Davydova and V.A. Sazonova: Fiz. Met. Metalloved., 1986, vol. 68, pp. 1170-1177.

6. A.P. Zhilyaev, G.V. Nurislamova, B.K. Kim, M.D. Baro, J.A. Szpunar and T.G. Langdon: Acta Mater., 2003, vol. 51 pp. 753-765.

7. V.V. Stolyarov, V.V. Latysh, R.Z. Valiev, Y.T. Zhu and T. Lowe: In Proceedings of the NATO ARW on Investigation and Application of Severe Plastic Deformation, ed. T. Lowe and R. Valiev, Moscow, Dordercht, Russia, 1999, p. 367.

8. V.S. Zhernakov, V.V. Latysh, V.V. Stolyarov, A.I. Zharikov and R.Z. Valiev: Scripta Mater., 2001, vol. 44, pp. 1771-1774.

9. R. Z. Valiev, I. P. Semenova, E. Jakushina, V.V. Latysh, H. Rack, T.C. Lowe, J. Petruzelka, L. Dluhos, D. Hrusak and J. Sochova: Mater. Sci. Forum, 2008, vol. 584-586, pp. 49-54.

10. S. Faghihi, A.P. Zhilyaev, J.A. Szpunar, F. Azari, H. Vali, and M. Tabrizian: Adv. Mater., 2007, vol. 19 pp. 1069-1073.

11. A.A. Propov, Y.U.I. Pyshmintsev, S.L. Demakov, A.G. Illarionov, T.C. Lowe, A.V. Segeyeva and R.Z. Valiev: Scripta Mater., 1997, vol. 37, pp. 1089-1094.

12. A.V. Sergueeva, V.V. Stolyarov, R.V. Valiev and A.K. Mukhrjee: Scripta Mater., 2001, vol. 45, pp. 747-752.

13. D.H. Shin, I. Kim, J. Kim, Y.S. Kim and S.L. Semiatin: Acta Mater., 2003, vol. 51, pp. 983-996.

14. A.Y. Vinogradov, V.V. Stolyarov, S. Hashimoto and R.Z. Valiev: Mater. Sci. Eng. A, 2001, vol. 
318, pp. 163-173.

15. V.V. Stolyarov, Y.T. Zhu, T.C. Lowe, R.K. Islamgaliev and R.Z. Valiev: Nanostruct. Mater., 1999, vol. 11, pp. 947-954.

16. R.Z. Valiev, A.V. Sergueeva, A.K. Mukherjee: Scripta Mater., 2003, vol. 49, pp. 669-674.

17. V.V. Stolyarov, Y.T. Zhu, I.V. Alexandrov, T.C. Lowe and R.Z. Valiev: Mater. Sci. Eng. A, 2003, vol. 343, pp. 43-50.

18. V.V. Stolyarov, Y.T. Zhu, G.I. Raab, A.I. Zharikov and R.Z. Valiev: Mater. Sci. Eng. A, 2004, vol. 385, pp. 309-313.

19. Y.T. Zhu, J.Y. Huang, J. Gubicza, T. Ungar, Y.M. Wang, E. Ma and R.Z. Valiev: J. Mater. Res. 2003, vol. 18(8), pp. 1908-1917.

20. D. Terada, S. Inoue and N. Tsuji: J. Mater. Sci., 2007, vol. 42, pp. 1673-1681.

21. G.A. Salishchev, R.M. Galeyev, S.P. Malysheva and M.M. Myshleaev: Nanostruct. Mater. 1999, vol. 11(3), pp. 407-414.

22. K.J. Kurzydłowski, H. Garbacz and M. Richert: Rev. Adv. Mater. Sci., 2004, vol. 8, pp. 129-133.

23. J. Dutkiewicz, J. Kusnierz, W. Maziarz, M. Lejkowska, H. Garbacz, M. Lewandowska, A.V. Dobromyslov and K.J. Kurzydlowski: Phys. Stat. Sol., 2005, vol. 202(12), pp. 2309-2320.

24. V.N. Varyukhin and B.M. Efros: In Proceedings of Nanostructured Materials by High-Pressure Severe Plastic Deformation, ed. Y.T. Zhu and V. Varyukhin, Dordrecht, the Netherland: Springer, 2006, vol. 212, pp. 13-20.

25. A.R. Kutsar: Fiz. Metal. Metalloved., 1975, vol. 40, pp. 786-793.

26. S.K. Sikka, Y.K. Vohra and R. Chidambaram: Prog. Mater. Sci., 1982, vol. 27, pp. 245-310.

27. Y. K. Vohra, S.K. Sikka, S.N. Vaidya and R. Chidamberan: J. Phys. Chem. Solids, 1977, vol. 38(11), pp. 1293-1296.

28. C.W. Greeff, D.R. Trinkle and R.C. Albert: J. Appl. Phys., 2001, vol. 90(5), pp. 2221-2226.

29. D. Errandonea, Y. Meng, M. Somayazulu and D. Haussermann: Physica B, 2005, vol. 355, pp. 116-125.

30. Y.K. Vohra and P.T. Spencer: Phys. Rev. Lett., 2001, vol. 86(14), pp. 3068-3071.

31. Y. Akahama, H. Kawamura and T.L. Bihan: Phys. Rev. Lett., 2001, vol. 87 p. 275503.

32. A.R. Kilmametov, A.V. Khristoforova, G. Wilde and R.Z. Valiev, Z. Kristallogr. Suppl., 2007, vol. 26, pp. 339-344.

33. Y. Todaka, J. Sasaki, T. Moto and M. Umemoto: Scripta Mater., 2008, vol. 59, pp. 615-618.

34. Y.H. Zhao, Y.Z. Guo, Q. Wei, A.M. Dangelewicz, C. Xu, Y.T. Zhu, T.G. Langdon, Y.Z. Zhou and E.J. Lavernia: Scripta Mater., 2008, vol. 59, pp. 627-630.

35. Y. Harai, Y. Ito and Z. Horita: Scripta Mater., 2008, vol. 58, pp. 469-472.

36. Y. Ito, Y. Harai, T. Fujioka, K. Edalati and Z. Horita: Mat. Sci. Forum, 2008, vol. 584-

37. K. Edalati, T. Fujioka and Z. Horita: Mater. Sci. Eng. A, 2008, vol. 497, pp. 168-173.

38. K. Edalati, T. Fujioka and Z. Horita: Mater. Trans., 2009, vol. 50, pp. 44-50.

39. A. Vorhauer and R. Pippan: Scripta Mater., 2004, vol. 51, pp. 921-925.

40. K. Edalati, Z. Horita and T.G. Langdon: Scripta Mater., 2009, vol. 60, pp. 9-12.

41. J.M. Silcock: Acta Metall., 1958, vol. 6, pp. 481-493.

42. K. Edalati, T. Fujioka, and Z. Horita: Proc. 156th Meeting of ISIJ and JIM: Joint Session on Current Advances in Materials and Processes, The Japan Insitute of Metals, Sendai, Japan, 2008, vol. 21 (2), p. 516.

43. R.Z. Valiev, Y.V. Ivanisenko, E.F. Rauch and B. Baudelet: Acta Mater., 1996, vol. 44, pp. 4705-4712.

44. M.J. Zehetbauer, H.P. Stuwe, A. Vorhauer, E. Schafler and J. Kohout: Adv. Eng. Mater., 2003, vol. 5(5), pp. 330-337. 